\title{
Aa. Vv., «Cahiers Tristan l'Hermite», XXXI
}

\section{Daniela Dalla Valle}

\section{(2) OpenEdition}

\section{Journals}

\section{Edizione digitale}

URL: http://journals.openedition.org/studifrancesi/6608

DOI: 10.4000/studifrancesi.6608

ISSN: 2421-5856

\section{Editore}

Rosenberg \& Sellier

\section{Edizione cartacea}

Data di pubblicazione: 1 septembre 2010

Paginazione: 357

ISSN: 0039-2944

\section{Notizia bibliografica digitale}

Daniela Dalla Valle, «Aa. Vv., «Cahiers Tristan I'Hermite», XXXI», Studi Francesi [Online], 161 (LIV | II) |

2010, online dal 30 novembre 2015, consultato il 11 janvier 2021. URL: http://

journals.openedition.org/studifrancesi/6608 ; DOI: https://doi.org/10.4000/studifrancesi.6608

\section{Questo documento è stato generato automaticamente il 11 janvier 2021.}

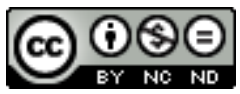

Studi Francesi è distribuita con Licenza Creative Commons Attribuzione - Non commerciale - Non opere derivate 4.0 Internazionale. 


\title{
Aa. Vv., «Cahiers Tristan l'Hermite», XXXI
}

\author{
Daniela Dalla Valle
}

\section{NOTIZIA}

«Cahiers Tristan l'Hermite», XXXI, 2009, Lire Tristan aujourd'hui, pp. 95.

1 L'edizione del 2009 dei «Cahiers Tristan l'Hermite» comprende gli atti di una giornata di studio su Tristan, dedicata appunto a studiare la sua lettura oggi.

2 La giornata è presentata da Florence ORWAT, ma soltanto alcune delle comunicazioni pubblicate si soffermano ad analizzare certi aspetti della lettura odierna di Tristan: sono quelle di Sandrine BERREGARD (che si sofferma sugli stessi «Cahiers», attivi da 30 anni) e di Patrick RIARD (che riferisce i risultati di un'inchiesta sul Page disgracié, molto meno noto oggi di quanto egli sperava). Le altre comunicazioni esplicitano, invece, una lettura-ovviamente moderna-di Tristan, senza sottoporre ad analisi questa modernità. Si tratta dei testi di Laurence RAULINE (anche lei lavora sul Page, rinviando i lettori alla sua tesi di dottorato Identité(s) libertine(s) di prossima pubblicazione presso Champion), di François DE LAAGE DE MEUX (che si occupa della posterità della metrica di Tristan, sempre nel XVII secolo), di Daniel BOVERo (che mette a confronto la poesia tristaniana con la pittura di Poussin), di Lionel PHILIPPs (che analizza La mort de Sénèque e La mort d'Agrippine di Cyrano, come tragedie della menzogna), di Myriam DUfOUR-MAITRE (su una variante della Carte du Royaume d'Amour).

3 Alcune illustrazioni accompagnano la comunicazione di Daniel Bovero; segue una bibliografia tristaniana. 